\title{
Room for Improvement: A 20-Year Single Center Experience with Allogeneic Stem Cell Transplantation for Myelodysplastic Syndromes
}

\author{
Katarzyna Duda $^{1} \cdot$ Agata Wieczorkiewicz-Kabut $^{1} \cdot$ Adrianna Spałek $^{1}$ • \\ Anna Koclęga ${ }^{1} \cdot$ Anna J. Kopińska $^{1} \cdot$ Krzysztof Woźniczka $^{1} \cdot$ Grzegorz Helbig $^{1}$ (1)
}

Received: 18 June 2021/ Accepted: 29 November 2021/Published online: 10 December 2021

(C) The Author(s) 2021

\begin{abstract}
Allogeneic stem cell transplantation (allo-SCT) remains the only curative therapeutic approach for patients with myelodysplastic syndromes (MDS). The aim of the study was to assess the efficacy/safety of allo-SCT as well as to identify factors influencing post-transplant survival. One hundred and two MDS patients (median age: 48 years; 57 males) who underwent allo-SCT were retrospectively evaluated. Twenty seven patients were transplanted from HLA-matched sibling and 75 patients received grafts from unrelated donors. Peripheral blood was a source of stem cell for 79 patients. Reduced intensity conditioning was used in 64 subjects. Acute and chronic graft versus host disease (GvHD) developed in 61 and 19 of patients, respectively. In total, 61 patients have died. The causes of deaths included infectious complications $(\mathrm{n}=30)$, steroidresistant GvHD ( $n=17)$, MDS relapse $(n=9)$ and transformation to AML $(n=5)$. Non-relapse mortality and cumulative incidence of relapse at 2 years were $49.8 \%$ and $9 \%$, respectively. 41 patients are alive at last contact and present full donor chimerism. 38 patients remain in complete hematological remission (CHR), 3 patients had CHR with incomplete platelet recovery. Median follow-up from diagnosis of MDS and transplantation are 27.1 months and 7 months respectively. Overall survival and relapse-free survival were $41 \%$ at 2 years. Increased serum ferritin level $>1000 \mathrm{ng} / \mathrm{ml}$, presence of acute GvHD, grades IIIIV acute GvHD and high hematopoietic cell transplantation-comorbidity index were found to negatively
\end{abstract}

Grzegorz Helbig

ghelbig@o2.pl

1 Department of Hematology and Bone Marrow

Transplantation, Medical School of Silesia, Silesian Medical

University, Dąbrowski Street 25, 40-032 Katowice, Poland influenced survival. Allo-SCT for MDS is feasible procedure with a proportion of patients to be cured.

Keywords Allogeneic stem cell transplantation · Graft versus host disease $\cdot$ Ferritin $\cdot$ Myelodysplastic syndromes · Overall survival

\section{Introduction}

Myelodysplastic syndromes (MDS) are a heterogeneous group of clonal hematopoietic disorders characterized by peripheral blood cytopenias and increased risk of progression to acute myeloid leukemia (AML). The course of MDS is highly variable-from indolent subtypes with long-term survival to the cases with very poor prognosis and rapid transformation to AML [1]. The prognosis of patient with MDS can be evaluated using various scoring systems - the most common are the International Prognostic Scoring System (IPSS) and its revised variantIPSS-R [2]. The choice of treatment is based on risk stratification and some patient-related factors (for example age, performance status, co-morbidities). Therapeutic approaches range from watchful-waiting strategy, supportive care, chemotherapy (hypomethylating agents, intensive induction chemotherapy) up to allogeneic stem cell transplantation (allo-SCT), the latter remains the only curative option [3]. According to the current recommendations, above all, allo-SCT should be offered for all fit patients with higher risk IPSS-R (high, very high and some cases from intermediate risk group-especially if score is over 3.5). Transplant strategy should also be considered for patients with lower risk IPSS-R scores, good performance and some poor risk factors (e.g. unfavorable cytogenetics, life-threatening cytopenias and high transfusion 
requirements). The upfront allo-SCT is recommended for patients with less than $10 \%$ marrow blasts. Patients with an increased marrow blast $\geq 10 \%$ should receive pre-transplant cytoreductive treatment (intensive chemotherapy or hypomethylating agents) [4]. Despite some advances in transplant strategies over the past decades, allo-SCT remains a high-risk procedure associated with transplantrelated complications and long-term survival rate of about $30-50 \%[2,5]$. In this report, we present our data on the impact of patient- and disease-related factors on the outcome of allo-SCT in patients with MDS.

\section{Materials and Methods}

The patients undergoing allogeneic stem cell transplantation in our center were retrospectively identified through the use of our institutional database of medical records. Diagnosis of MDS was made according to the 2001 World Health Organization criteria with subsequent updates [6-8] and the following categories were considered: MDS with single lineage dysplasia (MDS-SLD), MDS with multilineage dysplasia (MDS-MLD), MDS with ring sideroblasts (MDS-RS), MDS with isolated del5(q) and MDS with excess blasts 1 and 2 (MDS-EB1/2). A proportion of patients with $>10 \%$ of marrow blasts received pre-transplant cytoreductive therapy however the final decision was left to treating center. Cytogenetics was assessed at diagnosis on bone marrow cells using standard techniques. International Prognostic Scoring System (IPSS), its revised version (IPSS-R) and European Group for Blood and Marrow Transplantation (EBMT) risk score were calculated according to Greenberg et al. [9] and Gratwohl [10], respectively. The hematopoietic cell transplantation-comorbidity index (HCT-CI) was assessed according to Sorror et al. [11]. Bone marrow aspirate/biopsy was performed for response assessment at day $+30,+60,+100$ after transplantation and then every 6 months. Minimal residual disease (MRD) was not assessed. Molecular data were not available. The amplification of short tandem repeats (STRs) markers by polymerase chain reaction (PCR) in combination with fluorescence detection of the donor/recipient alleles by capillary electrophoresis was used for chimerism assessment [12]. Acute and chronic graft versus host disease (GvHD) were diagnosed and graded according to the standard criteria [13]. The transplantation was considered in fit patients with intermediate2/high IPSS and/or with (very) poor risk IPSS-R or intermediate/low or unknown IPSS(R) when patient remained transfusion dependent or had other poor risk features [4]. Patients were recruited from different centers in Poland hence not all data are available. The choice of treatment (hypomethylating agent or induction-like regimen) was left to treating physician. As per our local guidelines the induction-like regimen is given to patients with blast \% between 15 and $19 \%$. Our first patient on azacitidine was recruited in 2013. All patients provided an informed consent in accordance with the Declaration of Helsinki.

\section{Response Criteria}

Response after transplantation was estimated using International Working Group Criteria [14].

\section{Statistics}

There were following endpoints of interest: overall and relapse-free survivals (OS, RFS), cumulative incidence for non-relapse mortality (NRM) and for relapse (CIR). Time to event was assessed from the day of transplantation. Overall survival (OS) was defined as time from day of transplant to death from any cause. Relapse-free survival (RFS) was defined as the time from stem cell infusion to disease relapse, progression or death from any cause, whichever occurred first. Non-relapse mortality (NRM) was defined as any death before clinical progression or disease recurrence; relapse is considered as competing event. Relapse incidence (RI) defined the time from transplantation to first relapse or progression; death without relapse/progression is a competing event. Patient, treatment and transplant-related data were compared by MannWhitney test for continuous variables and chi-square test for categorical variables. The distribution for OS and RFS were estimated using Kaplan and Meier method and compared using the log-rank test, whereas the distribution of NRM and CIR were estimated by Cumulative Incidence Function and compared using the Gray's test. A $p<0.05$ was considered significant. The variables tested for prognostic significance for OS, RFS, NRM and CIR included patient-related data (age, gender, MDS type, blast proportion in blood and marrow, hemoglobin concentration, platelet count, neutrophil count, serum ferritin level, IPSS-R, cytogenetics), treatment-related data (the administration of hypomethylating agents and induction regimens) and transplant-related data (donor's age and gender, CMV status, ABO blood group, HLA compliance, the presence and grading of acute and chronic GvHD, the number of transplanted CD34 and CD3-positive cells). Proportional hazard models (Cox regression) were fitted to investigate effects of prognostic factors for OS and RFS, moreover the Fine-Gray subdistribution hazard models were used in case of NRM and CIR. Results were expressed as hazard ratio (HR) with 95\% confidence interval (CI). All computations were performed with StatSoft Poland analysis software (version 12.0) and SAS version 9.4 (SAS Institute Inc., Cary, North Carolina, USA). 


\section{Results}

\section{Patient Characteristics}

One hundred and two patients (45 females and 57 males) with MDS at median age of 47 years at diagnosis (range 18-72) underwent allo-SCT between years 2000 and 2020. Patients with different subtypes of MDS were enrolled into the study and MDS-MLD and EB2 were the most common. Data on IPSS and IPSS-R were available for 80 patients; 35 (44\%) of them showed intermediate-2/high and high/very high risk category, respectively. Cytogenetics on bone marrow cells were conclusive in 80 patients; 33 (41\%) individuals demonstrated diploid karyotype. Among cytogenetic abnormalities complex karyotype was most frequently observed (24\%). The treatment before transplantation varied and corticosteroids and cyclosporine were most commonly used. In total, 36 patients received debulking therapy before transplantation due to increased proportion of blast cells in bone marrow (21 patients received azacitidine and 15 subjects were treated with AML-like induction: daunorubicin/cytarabine). As a result, 13 out of the 36 treated patients $(36 \%)$ had $<10 \%$ blasts in $\mathrm{BM}$ before transplantation. The proportion of blasts was $>10 \%$ but $<19 \%$ in the remaining 23 patients. More than $50 \%$ of individuals were red blood cells (RBCs)-dependent at transplant, more than $30 \%$ of patients required regular platelet transfusion. Median blast proportion in blood and marrow at transplant was $0 \%$ (range 0-12) and $3 \%$ (range 0-19), respectively. Serum ferritin level was measured before conditioning and its median level was $1200.4 \mathrm{ng} / \mathrm{ml}$ (range 4.1-8841). Patients' characteristics is shown in Table 1.

\section{Transplant Data}

\section{Baseline Characteristics of Transplanted Patients}

Median recipient age was 48 years (range 18-72) whereas donors were significantly younger-32 years (range 16-67). Median time from diagnosis of MDS to transplantation was 10.9 months (range 1.9-131). Twenty seven patients were transplanted from HLA-matched sibling and 75 patients received either 10/10 HLA-matched unrelated donor $(n=60)$ or 9/10 HLA-mismatched grafts $(n=15)$. Peripheral blood was a source of stem cell for 79 patients. Reduced intensity conditioning (RIC) was used in 64 subjects whereas myeloablative regimen (MAC) was given in 38 individuals. MAC consisted of busulfan and cyclophosphamide and fludarabine-based regimens were given as RIC. GvHD prophylaxis included cyclosporine with methotrexate. Anti-thymocyte globulin
(Thymoglobulin) at $5 \mathrm{mg} / \mathrm{kg}$ b.w. was given for unrelated transplantations. Low hematopoietic cell transplant-comorbidity index (HCT-CI) and high European Bone Marrow Transplant (EBMT) score were calculated in most patients.

\section{Outcome of Transplanted Patients}

There were two primary graft failures (PGF) and those patients proceeded to second allo-SCT from the same donor. Median time to engraftment for the remaining study population was 15 days (range 11-100). Acute and chronic GvHD developed in $61(61 \%)$ and $19(19 \%)$ of patients, respectively. Acute GvHD grade III-IV developed after median of 17 days (range 8-98) and was present in 20 patients. Four patients had severe chronic GvHD. Infectious complications were commonly seen early after transplantation and included 50\% of transplanted population. 18 individuals developed pneumonia which resulted in septic shock and multiorgan dysfunction in 4 patients. Six patients had BKV-related hemorrhagic cystitis. CMV reactivation was demonstrated in 34 patients. Serious noninfectious complications were seen in 22 patients; 3 patients developed veno-occlusive disease (VOD), capillary leak syndrome (CLS) was seen in 2 patients and one individual had thrombotic thrombocytopenic purpura (TTP). Two patients had hemorrhagic complications; gastrointestinal bleeding and intracerebral hemorrhage. Eleven patients died within the first 30 days and 29 died during 100 days after transplantation. Fifty four deaths were noted within the first year after allo-SCT. The remaining 7 deaths occurred $>1$ year after procedure. The causes of death within the first 30 days after transplantation included pneumonia $(\mathrm{n}=8)$, VOD with CLS $(\mathrm{n}=1)$, TTP $(\mathrm{n}=1)$ and intracerebral bleeding $(\mathrm{n}=1)$. Post transplant bone marrow assessment was performed in 74 patients at day $+100 \pm 7$ days and demonstrated complete remission in 48 patients, 9 patients had stable disease, 12 patients remained transfusion dependent and 5 patients transformed into AML. All the latter patients had pre-transplant BM blast $>5 \%$.

In total, 61 patients have died. The main causes of death included infectious complications $(\mathrm{n}=30)$, steroid-resistant GvHD ( $\mathrm{n}=17)$, relapse with subsequent resistance to treatment $(\mathrm{n}=9)$ and transformation to AML $(\mathrm{n}=5)$.

41 patients are alive at last contact and present full donor chimerism. 38 patients remain in $\mathrm{CR}, 3$ had $\mathrm{CR}$ with incomplete platelet recovery, but remained transfusion-independent. Median follow-up from diagnosis of MDS and transplantation are 27.1 months and 7 months respectively. Transplant data are summarized in Table 2 . The probability of OS and relapse-free survival (RFS) were $41 \%$ at 2 years. Non-relapse mortality (NRM) and cumulative incidence of 
Table 1 Patient characteristics

\begin{tabular}{|c|c|}
\hline Variable & $\mathrm{n}=102$ \\
\hline Gender (female/male) & $45 / 57$ \\
\hline Age at diagnosis, years; median (range) & $47(18-72)$ \\
\hline \multicolumn{2}{|l|}{ MDS subtype at diagnosis, $\mathrm{n}$} \\
\hline MDS-SLD/RS/5q & 16 \\
\hline MDS-MLD & 47 \\
\hline MDS-EB1 & 9 \\
\hline MDS-EB2 & 30 \\
\hline \multicolumn{2}{|l|}{ IPSS, $\mathrm{n}^{\mathrm{a}}$} \\
\hline Low & 11 \\
\hline Int-1 & 34 \\
\hline Int-2 & 26 \\
\hline High & 9 \\
\hline \multicolumn{2}{|l|}{ IPSS-R $\mathrm{R}^{\mathrm{a}}$} \\
\hline Very low & 9 \\
\hline Low & 17 \\
\hline Intermediate & 19 \\
\hline High & 21 \\
\hline Very high & 14 \\
\hline \multicolumn{2}{|l|}{ Treatment for MDS, $\mathrm{n}$} \\
\hline Steroids & 46 \\
\hline CsA & 13 \\
\hline Androgens & 6 \\
\hline ATG & 3 \\
\hline Lenalidomide & 3 \\
\hline TPO agonist & 2 \\
\hline EPO & 4 \\
\hline LD Ara-C & 5 \\
\hline Azacitidine & 21 \\
\hline AML-induction & 15 \\
\hline No treatment & 27 \\
\hline Red blood cell transfusion dependence, $\mathrm{n}$ & 58 \\
\hline Platelet transfusion dependence, $\mathrm{n}$ & 37 \\
\hline Time from MDS diagnosis to transplant, months; median (range) & $10.9(1.9-131)$ \\
\hline
\end{tabular}

AML, acute myeloid leukemia; Ara-C, cytarabine; ATG, anti-thymocyte globulin; CsA, cyclosporine; EB, excess of blasts; EPO, erythropoietin; IPSS, international prognostic scoring system; LD, low dose; MDS, myelodysplastic syndrome; MLD, multilineage dysplasia; SLD, single lineage dysplasia; TPO, thrombopoietin; RS, ring sideroblasts; WHO, World Health Organization

${ }^{a}$ Data on 80 patients

relapse (CIR) at 2 years were $49.8 \%$ and $9 \%$, respectively (see Fig. 1). Median follow-up for survivors was 49.7 months (range 3.46-192.0).

\section{Univariable (UVA) and Multivariable Analysis (MVA) of Risk Factors}

Overall Survival The following factors influenced OS in UVA: HCT-CI, serum ferritin level, the presence of acute GvHD, acute GvHD grading, EBMT score and year of transplantation. All but year of transplantation and EBMT score negatively influenced survival in MVA (see Fig. 2). Neither IPSS and IPSS-R nor type of conditioning, type of donor, year of transplantation and blast percentage before transplantation affected survival.

Relapse-Free Survival The same set of variables as for OS influenced RFS in UVA, but statistical significance was demonstrated for HCT-CI, acute GvHD, acute GvHD grading and serum ferritin level in MVA. 
Table 2 Transplant data

\begin{tabular}{|c|c|}
\hline Variable & $\mathrm{n}=102$ \\
\hline Age of recipient, median; years (range) & $48(19-72)$ \\
\hline Age of donor, median; years (range) & $32(16-67)$ \\
\hline \multicolumn{2}{|l|}{ Year of transplant, $\mathrm{n}$} \\
\hline$<2010$ & 27 \\
\hline $2010-2015$ & 38 \\
\hline$>2015$ & 37 \\
\hline \multicolumn{2}{|l|}{ EBMT score; $\mathrm{n}$} \\
\hline Low & 6 \\
\hline Intermediate & 36 \\
\hline High & 60 \\
\hline \multicolumn{2}{|l|}{ HCT-CI score; n } \\
\hline Low & 74 \\
\hline Intermediate & 19 \\
\hline High & 9 \\
\hline \multicolumn{2}{|l|}{ Donor type, $\mathrm{n}$} \\
\hline Matched related & 27 \\
\hline 10/10-HLA matched unrelated & 60 \\
\hline 9/10-HLA matched unrelated & 15 \\
\hline \multicolumn{2}{|l|}{ Graft source } \\
\hline Peripheral blood & 79 \\
\hline Bone marrow & 23 \\
\hline Hemoglobin level (g/dL); median (range) & $9.1(3.5-15.8)$ \\
\hline Neutrophil count $\left(\times 10^{9} / \mathrm{L}\right) ;$ median (range) & $1.2(0.07-10.9)$ \\
\hline Platelet count $\left(\times 10^{9} / \mathrm{L}\right) ;$ median (range) & $44(1-634)$ \\
\hline Blast percentage in blood; median (range) & $0(0-12)$ \\
\hline Blast percentage in bone marrow; median (range) & $0(0-19)$ \\
\hline Ferritin level (ng/ml); median (range) ${ }^{a}$ & $1200.4(4.1-8841)$ \\
\hline$<1000 \mathrm{ng} / \mathrm{ml} ; \mathrm{n} ; \%$ & $32(44)$ \\
\hline$\geq 1000 \mathrm{ng} / \mathrm{ml} ; \mathrm{n} ; \%$ & $41(56)$ \\
\hline Myeloablative conditioning, $\mathrm{n}$ & 38 \\
\hline \multicolumn{2}{|l|}{ Conditioning regimen, $\mathrm{n}$} \\
\hline Busulfan/Cyclophosphamide & 38 \\
\hline Treosulfan/Fludarabine & 37 \\
\hline Busulfan/Fludarabine & 18 \\
\hline Other & 9 \\
\hline Number of transplanted CD34-positive cells $\left(\times 10^{6} / \mathrm{kg}\right)$; median (range) & $5.05(0.8-13.9)$ \\
\hline Neutrophil engraftment; days, median (range) & $15(11-100)$ \\
\hline Platelet engraftment; days, median (range) & $18(10-55)$ \\
\hline \multicolumn{2}{|l|}{ Acute GvHD, n } \\
\hline Grade I-II & 41 \\
\hline Grade III-IV & 20 \\
\hline Chronic GvHD, n & 19 \\
\hline Median follow-up from transplantation, months; median (range) & $7.05(0.13-192)$ \\
\hline Median follow-up from MDS diagnosis, months; median (range) & $27.1(5.3-204.2)$ \\
\hline
\end{tabular}

EBMT, European Blood and Bone Marrow Transplantation; GvHD, graft versus host disease; HCT-CI, hematopoietic cell transplant comorbidity index

${ }^{\mathrm{a}}$ Data on 73 patients 

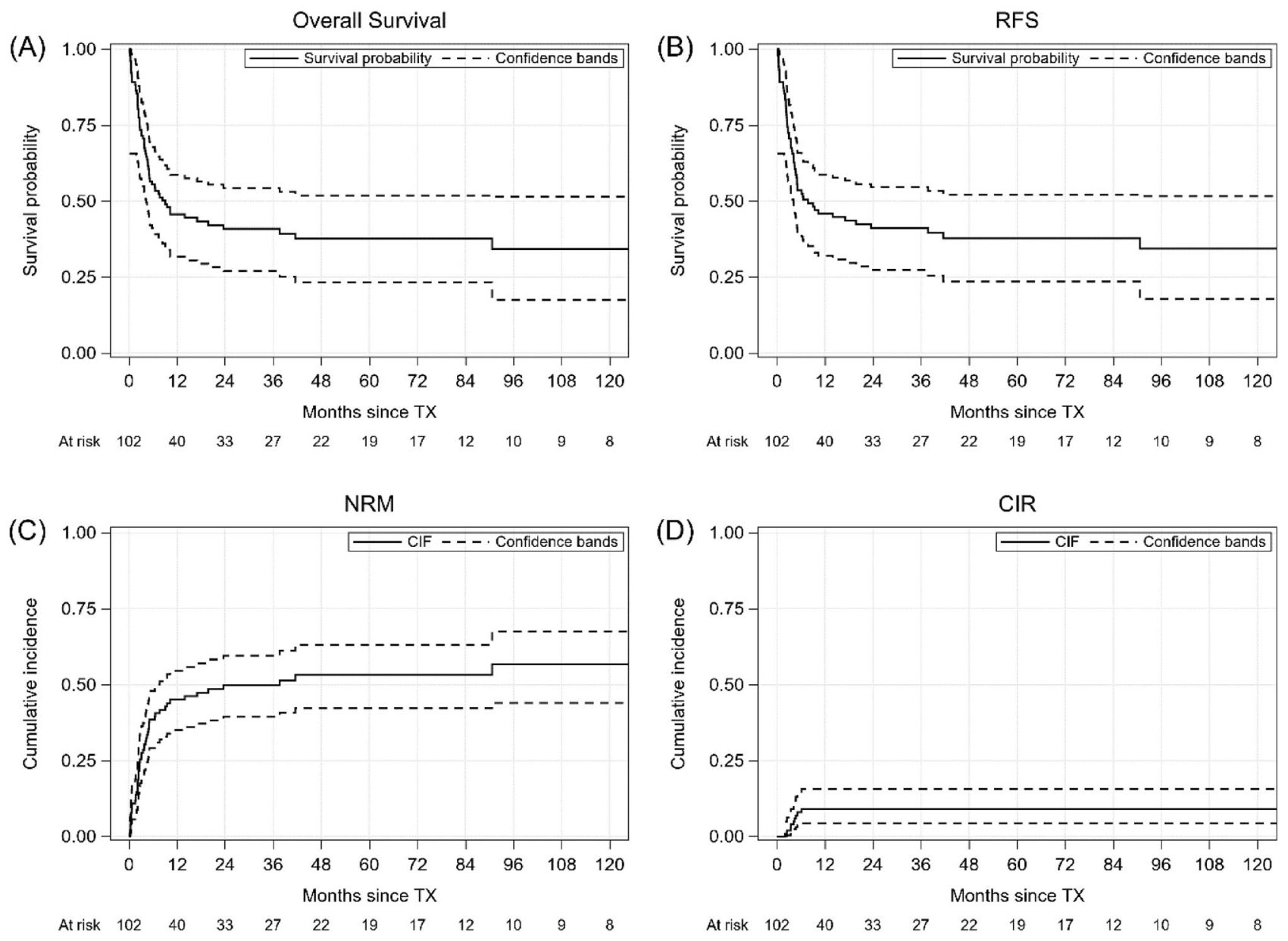

Fig. 1 OS, RFS, NRM and CIR for allotransplanted MDS patients

Non-relapse Mortality The presence of acute GvHD, acute GvHD grading and CMV reactivation had an impact on NRM in UVA, but only acute GvHD grading remained significant in MVA.

Cumulative Incidence of Relapse Blast percentage in bone marrow at transplant, EBMT score and acute GvHD grading influenced CIR in UVA, but only EBMT score was significant in MVA.

Details were present in Table 3.

\section{Discussion}

Allo-SCT remains the only curative therapeutic approach for patients with MDS, however the procedure is related to significant morbidity and mortality. A weighed assessment of benefit and risk of transplantation should be done before taking a final decision. Lower risk patients can experience long-term survival with stable disease and they would not benefit from an early SCT. These patients have better life

expectancy when transplantation is delayed until disease progression or treatment failure [15-17]. Nonetheless, alloSCT should be considered in patients with good performance and poor prognostic factors defined as poor-risk cytogenetic characteristics, high transfusion burden or lifethreatening cytopenias [18]. Patients with higher risk MDS have a poor prognosis and increased risk of transformation to acute leukemia with the median OS $<2$ years. However, not all these patients can be candidates for allogeneic transplant due to advanced age or co-morbidities.

In our study, the estimated 2-year OS was $41 \%$ and our findings were similar to those reported by others [19-21]. In a large study of the European Group for Blood and Marrow Transplantation (EBMT), the 3-year disease-free survival of 712 patients transplanted for primary MDS from 1983 to 1998 was 37\% [22]. Other large registry reported overall survival rates of $42 \%$ at 3 years on 452 cases of HLA-identical sibling donor transplantation [23]. The probability of survival of 510 patients with MDS who underwent unrelated donor bone marrow transplantation at 2 years was 30\% [24]. The introduction of RIC regimens 

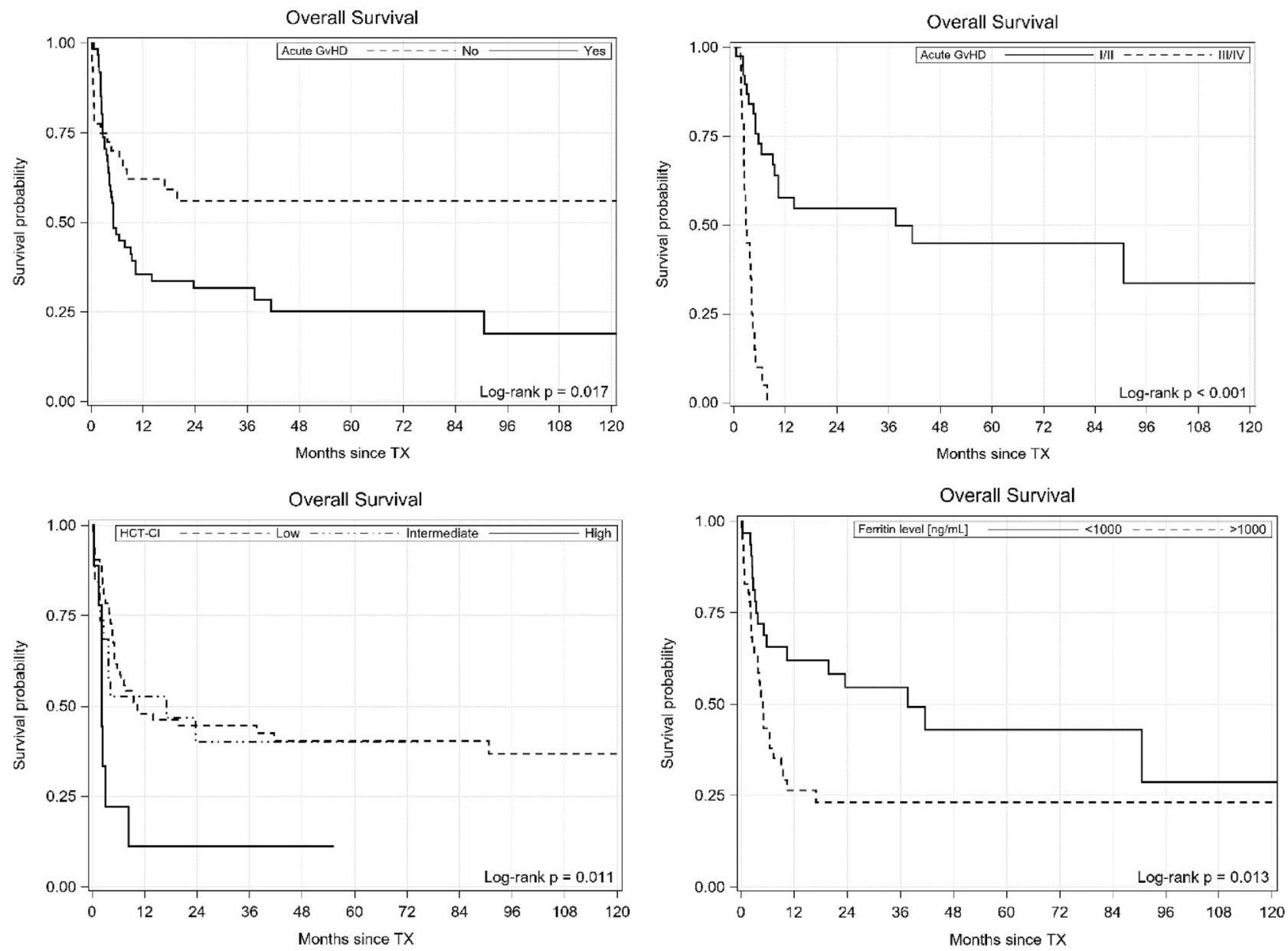

Fig. 2 Survival outcomes according to the presence of acute GvHD, acute GvHD grading, HCT-CI and serum ferritin level

provided the possibility of transplantation for older patients with 2-4-year OS rates ranging from 23 to $75 \%$ [25-29]. Better results were reported in a more recent prospective study-overall survival at 2 years was $76.3 \%$ after RIC and $63.2 \%$ after myeloablative conditioning [30]. Although allo-SCT is potentially curative, it carries a high risk of non-relapse mortality (NRM). The incidence of NRM ranges from $36 \%$ even to $66 \%$ [22-30]. In our study NRM was in line with those provided by others and reached $50 \%$ at 2 years.

We analyzed impact of pretransplant and transplant factors affecting patients' survival. The EBMT risk score provides a simple tool to assess chances and risks of alloSCT for an individual patient [10]. In our study EBMT score tended to affect survival in univariable analysis but it was found not to influence survival in multivariable analysis-OS at 2 years for patients with low EBMT score was $83 \%$ when compared with $34 \%$ and $29 \%$ for intermediate and high-risk EBMT scores, respectively. Our findings are similar to Lozano study, in which 9741 patients with MDS were included [31]. In that report the EBMT score accurately predicted OS at 5 years-50\%, $41 \%$ and $31 \%$ for high, intermediate and low risk scores respectively. It also correlated with incidence of treatment-related mortality. No differences in the relapse risk among EBMT score groups were observed.

Our results demonstrated that iron overload measured by pre-transplantation serum ferritin level had a negative impact on OS after allo-SCT. These findings are in agreement with the previous studies [32-34]. Moreover, some of these reports have also showed that serum ferritin level was found to be a risk factor for development of severe infections and acute GvHD. Cremers et al. demonstrated that patients with serum ferritin level $\geq 1000 \mathrm{ng} / \mathrm{ml}$ had a $14 \%$ lower 2-year survival, higher NRM and relapse incidence than patients with serum ferritin level below $1000 \mathrm{ng} / \mathrm{ml}$ [35]. Pretransplant serum ferritin level has also been included in a prognostic score for patients with acute leukemia or MDS undergoing allo-SCT [36]. Armand et al. proposed a scoring system based on 5 variables (age, disease, stage at transplantation, cytogenetics, and pre-transplantation ferritin), which divided patients into 3 groups 
Table 3 Univariable and multivariable analysis of risk factor for OS, RFS, NRM and CIR (Cox regression)

\begin{tabular}{|c|c|c|c|}
\hline Variable (n) & $p$ value & $\mathrm{HR}(95 \% \mathrm{CI})$ & $p$ value \\
\hline \multicolumn{4}{|c|}{ Univariable and multivariable analysis of risk factor for overall survival } \\
\hline HCT-CI & 0.004 & $5.06(1.06-24.1)$ & 0.01 \\
\hline \multicolumn{4}{|l|}{ Low (74) } \\
\hline \multicolumn{4}{|l|}{ Intermediate (19) } \\
\hline \multicolumn{4}{|l|}{ High (9) } \\
\hline Acute GvHD & 0.01 & $8.37(0.98-71.6)$ & 0.017 \\
\hline \multicolumn{4}{|l|}{ Yes $(61)$} \\
\hline \multicolumn{4}{|l|}{ No $(41)$} \\
\hline Acute GvHD & $<0.001$ & $8.71(2.77-27.3)$ & $<0.001$ \\
\hline \multicolumn{4}{|l|}{ GI-GII (41) } \\
\hline \multicolumn{4}{|l|}{ GIII-GIV (20) } \\
\hline Serum ferritin level & 0.01 & $2.84(1.09-7.27)$ & 0.01 \\
\hline \multicolumn{4}{|l|}{$<1000 \mathrm{ng} / \mathrm{ml}(32)$} \\
\hline \multicolumn{4}{|l|}{$\geq 1000 \mathrm{ng} / \mathrm{ml}(41)$} \\
\hline Transplant year & 0.03 & $1.08(0.43-2.73)$ & 0.11 \\
\hline \multicolumn{4}{|l|}{$<2010(27)$} \\
\hline \multicolumn{4}{|l|}{ 2010-2015 (38) } \\
\hline \multicolumn{4}{|l|}{$>2015(37)$} \\
\hline EBMT score & 0.06 & $0.98(0.62-1.55)$ & 0.9 \\
\hline \multicolumn{4}{|l|}{ Low (9) } \\
\hline \multicolumn{4}{|l|}{ Intermediate (36) } \\
\hline \multicolumn{4}{|l|}{ High (60) } \\
\hline \multicolumn{4}{|c|}{ Univariable and multivariable analysis of risk factor for relapse-free survival } \\
\hline HCT-CI & 0.003 & $5.93(1.20-29.12)$ & 0.008 \\
\hline \multicolumn{4}{|l|}{ Low (74) } \\
\hline \multicolumn{4}{|l|}{ Intermediate (19) } \\
\hline \multicolumn{4}{|l|}{ High (9) } \\
\hline Acute GvHD & 0.02 & $7.59(0.9-63.4)$ & 0.01 \\
\hline \multicolumn{4}{|l|}{ Yes (61) } \\
\hline \multicolumn{4}{|l|}{ No (41) } \\
\hline Acute GvHD & $<0.001$ & $5.97(2.06-17.3)$ & $<0.001$ \\
\hline GI-GII (41) & & & \\
\hline GIII-GIV (20) & & & \\
\hline Serum ferritin level & 0.01 & $2.85(1.09-7.43)$ & 0.01 \\
\hline < $1000 \mathrm{ng} / \mathrm{ml}(32)$ & & & \\
\hline$\geq 1000 \mathrm{ng} / \mathrm{ml}(41)$ & & & \\
\hline Transplant year & 0.03 & $0.94(0.36-2.47)$ & 0.11 \\
\hline$<2010(27)$ & & & \\
\hline 2010-2015 (38) & & & \\
\hline$>2015(37)$ & & & \\
\hline Univariable and mul & alysis of ri & ton-relapse mortalit & \\
\hline Acute GvHD & 0.02 & $19.9(3.78-104.5)$ & 0.0004 \\
\hline Yes (61) & & & \\
\hline No (41) & & & \\
\hline Acute GvHD & $<0.001$ & $2.93(0.54-15.7)$ & 0.2 \\
\hline GI-GII (41) & & & \\
\hline GIII-GIV (20) & & & \\
\hline CMV reactivation & 0.03 & $2.24(0.85-5.9)$ & 0.1 \\
\hline Yes (34) & & & \\
\hline No (68) & & & \\
\hline
\end{tabular}


Table 3 continued

\begin{tabular}{lccc}
\hline Variable $(\mathrm{n})$ & $p$ value & HR $(95 \% \mathrm{CI})$ & $p$ value \\
\hline Univariable and multivariable analysis & of risk factor for & cumulative incidence relapse & \\
Blast \% in bone marrow at transplant & 0.03 & $1.02(0.89-1.17)$ & 0.7 \\
EBMT score & $<0.001$ & $0.63(0.02-16.51)$ & $<\mathbf{0 . 0 0 1}$ \\
Low (9) & & & \\
Intermediate (36) & & & \\
High (60) & $<0.001$ & $16.78(1.69-166.28)$ & 0.19 \\
Acute GvHD & & \\
GI-GII (41) & & \\
GIII-GIV (20) & &
\end{tabular}

Bold indicates statistical significance

with 5-year overall survival of 56\% (low risk), 22\% (intermediate risk), and 5\% (high risk). However, serum ferritin level is also widely recognized as an inflammatory marker and its role as a marker of iron overload should be considered with some caution.

Another factor that influenced OS was the occurrence of acute GvHD-a 2-year OS was significantly worse in patients who developed acute GvHD when compared with those who did not (31\% vs $56 \%$ ). GvHD was also one of the most common cause of death in transplanted patients (17 out of 61 died patients). Moreover, patients presented with grades I-II acute GvHD fared much better than those with grades III-IV (56\% vs $0 \%$ at 2 years; HR $8.71 ; 95 \%$ CI 2.77-27.3; $p<0.001)$. Grade III-IV acute GvHD developed in $20 \%$ patients (grades II-IV in $37 \%$ ) and our results were in line with those presented by other authors [23, 30, 31, 37]. In Oran study, the cumulative incidence of grade II-IV acute GvHD was 39\% and development of grade II-IV acute GvHD was associated with significantly shorter survival [25].

Surprisingly, patients transplanted before 2010 fared much better in UVA than those who received graft between 2010 and 2015 (52\% vs $29 \%$ at 2 years, respectively; data not published), however this finding was not confirmed in MVA.

In our study, transformation to AML or relapse occurred in $5(4.9 \%)$ and $9(8.8 \%)$ patients, respectively. All patients who progressed to leukemia had pre-transplant BM blast $>5 \%$ and $90 \%$ received cytoreduction therapy without achieving CR after treatment. It was demonstrated that treatment resistance before transplantation was a poor prognostic factor [16, 38-41]. The cumulative incidence of relapse at 2-4 years differs between reports-ranging from $6 \%$ to even to $46 \%$ in the high risk groups [23, 25, 41-43].

Our report has several limitations that should be acknowledged. This study was retrospective and included data from a single institution registry. Nonetheless, our report has demonstrated that allo-SCT is a potentially curative treatment option for proportion of patients with MDS. On the other hand, one should be aware of severe post-transplant complications including infections and steroid-resistant GVHD. A large prospective studies should be initiated to better define factors influencing survival after allo-SCT for MDS.

Author Contributions KD, GH—study design, data interpretation, writing the manuscript, statistical analysis, final revision of the manuscript, AWK, AS, AK, AJK, KW-data collection and interpretation, final revision of the manuscript.

Funding This research received no external funding.

\section{Declarations}

Conflict of interests All authors declared that they have no conflict of interest.

Ethical Approval All procedures performed in studies involving human participants were in accordance with the ethical standards of the institutional and/or national research committee and with the 1964 Helsinki declaration and its later amendments or comparable ethical standards. This article does not contain any animal studies performed by any of the authors.

Informed Consent Informed consent was obtained from all individual participants included in the study.

Open Access This article is licensed under a Creative Commons Attribution 4.0 International License, which permits use, sharing, adaptation, distribution and reproduction in any medium or format, as long as you give appropriate credit to the original author(s) and the source, provide a link to the Creative Commons licence, and indicate if changes were made. The images or other third party material in this article are included in the article's Creative Commons licence, unless indicated otherwise in a credit line to the material. If material is not included in the article's Creative Commons licence and your intended use is not permitted by statutory regulation or exceeds the permitted use, you will need to obtain permission directly from the copyright holder. To view a copy of this licence, visit http://creativecommons. org/licenses/by/4.0/. 


\section{References}

1. Malcovati L, Hellström-Lindberg E, Bowen D, Ades L, Cermak J, Del Canizo C et al (2013) Diagnosis and treatment of primary myelodysplastic syndromes in adults: recommendations from the European LeukemiaNet. Blood 122:2943-2964

2. Scalzulli E, Pepe S, Colafigli G, Breccia M (2020) Therapeutic strategies in low and high-risk MDS: what does the future have to offer? Blood Rev 45:100689

3. Fenaux P, Platzbecker U, Ades L (2020) How we manage adults with myelodysplastic syndrome. Br J Haematol 189:1016-1027

4. de Witte T, Bowen D, Robin M, Malcovati L, Niederwieser D, Yakoub-Agha I et al (2017) Allogeneic hematopoietic stem cell transplantation for MDS and CMML: recommendations from an international expert panel. Blood 129:1753-1762

5. Danielson N, Byrne M (2020) Indications for allogeneic hematopoietic cell transplantation in myelodysplastic syndrome. Curr Hematol Malig Rep 15:268-275

6. Vardiman JW, Harris NL, Brunning RD (2002) The World Health Organization (WHO) classification of the myeloid neoplasms. Blood 100:2292-2302

7. Vardiman JW, Thiele J, Arber DA, Brunning RD, Borowitz MJ, Porwit A et al (2009) The 2008 revision of the World Health Organization (WHO) classification of myeloid neoplasms and acute leukemia: rationale and important changes. Blood 114:937-951

8. Arber DA, Orazi A, Hasserjian R, Thiele J, Borowitz MJ, Le Beau MM et al (2016) The 2016 revision to the World Health Organization classification of myeloid neoplasms and acute leukemia. Blood 127:2391-2405

9. Greenberg PL, Tuechler A, Schanz J, Sanz G, Garcia-Manero G, Sole F et al (2012) Revised international scoring system for myelodysplastic syndromes. Blood 120:2454-2465

10. Gratwohl A (2012) The EBMT risk score. Bone Marrow Transplant 47:749-756

11. Sorror ML, Maris MB, Storb R, Baron F, Sandmaier BM, Maloney DG, Storer B (2005) Hematopoietic cell transplantation (HCT)-specific comorbidity index: a new tool for risk assessment before allogeneic HCT. Blood 106:2912-2919

12. Lion T (2003) Summary: reports on quantitative analysis of chimerism after allogeneic stem cell transplantation by PCR amplification of microsatellite markers and capillary electrophoresis with fluorescence detection. Leukemia 17:252-254

13. Schoemans HM, Lee SJ, Ferrara JL, Wolff D, Levine JE, Schultz KR et al (2018) EBMT-NIH-CIBMTR Task Force position statement on standardized terminology \& guidance for graftversus-host disease assessment. Bone Marrow Transplant 53:1401-1415

14. Cheson BD, Greenberg PL, Bennett JM, Lowenberg B, Wijermans PW, Nimer SD et al (2006) Clinical application and proposal for modification of the International Working Group (IWG) response criteria in myelodysplasia. Blood 108:419-425

15. Cutler CS, Lee SJ, Greenberg P, Deeg HJ, Perez WS, Anasetti C et al (2004) A decision analysis of allogeneic bone marrow transplantation for the myelodysplastic syndromes: delayed transplantation for low-risk myelodysplasia is associated with improved outcome. Blood 104:579-585

16. Robin M, Porcher R, Zinke-Cerwenka W, van Biezen A, Volin L, Mufti G et al (2017) Allogeneic haematopoietic stem cell transplant in patients with lower risk myelodysplastic syndrome: a retrospective analysis on behalf of the Chronic Malignancy Working Party of the EBMT. Bone Marrow Transplant 52:209-215

17. Fenaux P, Adès L (2013) How we treat lower-risk myelodysplastic syndromes. Blood 21:4280-4286
18. Arslan S, Nakamura R (2020) Decision analysis of transplantation for patients with myelodysplasia: "Who Should We Transplant Today?" Curr Hematol Malig Rep 15:305-315

19. Warlick ED, Cioc A, Defor T, Dolan M, Weisdorf D (2009) Allogeneic stem cell transplantation for adults with myelodysplastic syndromes: importance of pretransplant disease burden. Biol Blood Marrow Transplant 15:30-38

20. McClune BL, Weisdorf DJ, Pedersen TL, da Silva GT, Tallman MS, Sierra J et al (2010) Effect of age on outcome of reducedintensity hematopoietic cell transplantation for older patients with acute myeloid leukemia in first complete remission or with myelodysplastic syndrome. J Clin Oncol 28:1878-1887

21. Deeg HJ, Scott BL, Fang M, Shulman HM, Gyourkocza B, Myerson D et al (2012) Five-group cytogenetic risk classification, monosomal karyotype, and outcome after hematopoietic cell transplantation for MDS or acute leukemia evolving from MDS. Blood 120:1398-1408

22. de Witte T, Hermans J, Vossen J, Bacigalupo A, Meloni G, Jacobsen $\mathrm{N}$ et al (2000) Haematopoietic stem cell transplantation for patients with myelo-dysplastic syndromes and secondary acute myeloid leukaemias: a report on behalf of the Chronic Leukaemia Working Party of the European Group for Blood and Marrow Transplantation (EBMT). Br J Haematol 110:620-630

23. Sierra J, Pérez WS, Rozman C, Carreras E, Klein JP, Rizzo JD et al (2002) Bone marrow transplantation from HLA-identical siblings as treatment for myelodysplasia. Blood 100:1997-2004

24. Castro-Malaspina H, Harris RE, Gajewski J, Ramsay N, Collins $\mathrm{R}$, Dharan B et al (2002) Unrelated donor marrow transplantation for myelodysplastic syndromes: outcome analysis in 510 transplants facilitated by the National Marrow Donor Program. Blood 99:1943-1951

25. Oran B, Giralt S, Saliba R, Hosing C, Popat U, Khouri S et al (2007) Allogeneic hematopoietic stem cell transplantation for the treatment of high-risk acute myelogenous leukemia and myelodysplastic syndrome using reduced-intensity conditioning with fludarabine and melphalan. Biol Blood Marrow Transplant 13:454-462

26. Laport GG, Sandmaier BM, Storer BE, Scott BL, Stuart MJ, Lange $\mathrm{T}$ et al (2008) Reduced-intensity conditioning followed by allogeneic hematopoietic cell transplantation for adult patients with myelodysplastic syndrome and myeloproliferative disorders. Biol Blood Marrow Transplant 14:246-255

27. Nakamura R, Rodriguez R, Palmer J, Stein A, Naing A, Tsai N et al (2007) Reduced-intensity conditioning for allogeneic hematopoietic stem cell transplantation with fludarabine and melphalan is associated with durable disease control in myelodysplastic syndrome. Bone Marrow Transplant 40:843-850

28. Lim Z, Brand R, Martino R, van Biezen A, Finke J, Bacigalupo A et al (2010) Allogeneic hematopoietic stem-cell transplantation for patients 50 years or older with myelodysplastic syndromes or secondary acute myeloid leukemia. J Clin Oncol 28:405-411

29. Nakamura R, Palmer JM, O'Donnell MR et al (2012) Reduced intensity allogeneic hematopoietic stem cell transplantation for MDS using tacrolimus/sirolimus-based GVHD prophylaxis. Leuk Res 36:1152-1156

30. Kröger N, Iacobelli S, Franke GN, Platzbecker U, Uddin R, Hubel K et al (2017) Dose-reduced versus standard conditioning followed by allogeneic stem-cell transplantation for patients with myelodysplastic syndrome: a prospective randomized phase III study of the EBMT (RICMAC Trial). J Clin Oncol 35:2157-2164

31. Lozano S, Olavarria E, Iacobelli S, van Biezen A, Beelen D, Finke J et al (2015) The EBMT score predicts transplant related mortality and overall survival after allogeneic stem cell transplantation for myelodysplastic syndromes. Blood 126:3223

32. Pullarkat V, Blanchard S, Tegtmeier B, Dagis A, Patane K, Ito J, Forman SJ (2008) Iron overload adversely affects outcome of 
allogeneic hematopoietic cell transplantation. Bone Marrow Transplant 42:799-805

33. Pullarkat V (2010) Iron overload in patients undergoing hematopoietic stem cell transplantation. Adv Hematol 2010:345756

34. Armand P, Kim HT, Cutler CS, Ho WT, Koreth J, Elyea EP et al (2007) Prognostic impact of elevated pretransplantation serum ferritin in patients undergoing myeloablative stem cell transplantation. Blood 109:4586-4588

35. Cremers EM, van Biezen A, de Wreede LC, Scholten M, Vitek A, Finke $J$ et al (2016) Prognostic pre-transplant factors in myelodysplastic syndromes primarily treated by high dose allogeneic hematopoietic stem cell transplantation: a retrospective study of the MDS subcommittee of the CMWP of the EBMT. Ann Hematol 95:1971-1978

36. Armand P, Kim HT, Cutler CS, Ho WT, Koreth J, Ritz J et al (2008) A prognostic score for patients with acute leukemia or myelodysplastic syndromes undergoing allogeneic stem cell transplantation. Biol Blood Marrow Transplant 14:28-35

37. Park SS, Jeon YW, Min GJ, Park S, Yahng SA, Yoon JH et al (2019) Graft-versus-host disease-free, relapse-free survival after allogeneic stem cell transplantation for myelodysplastic syndrome. Biol Blood Marrow Transplant 25:63-72

38. Konuma T, Shimomura Y, Ozawa Y, Ueda J, Uchida N, Onizuka $M$ et al (2019) Induction chemotherapy followed by allogeneic HCT versus upfront allogeneic HCT for advanced myelodysplastic syndrome: a propensity score matched analysis. Hematol Oncol 37:85-95

39. Modi D, Kim S, Singh V, Ayash L, Alavi A, Ratanatharathorn V et al (2019) Pre-transplant hypomethylating agents do not influence post-transplant survival in myelodysplastic syndrome. Leuk Lymphoma 60:2762-2770

40. Potter VT, Iacobelli S, van Biezen A, Maertens J, Bourhis JH, Passweg JR et al (2016) Comparison of intensive chemotherapy and hypomethylating agents before allogeneic stem cell transplantation for advanced myelodysplastic syndromes: a study of the myelodysplastic syndrome subcommittee of the chronic malignancies Working Party of the European Society for Blood and Marrow Transplant Research. Biol Blood Marrow Transplant 22:1615-1620

41. Scott BL, Storer B, Loken MR, Storb R, Appelbaum FR, Deeg HJ (2005) Pretransplantation induction chemotherapy and posttransplantation relapse in patients with advanced myelodysplastic syndrome. Biol Blood Marrow Transplant 11:65-73

42. Scheid C, de Wreede L, van Biezen A, Koenecke C, Goring G, Volin L et al (2017) Validation of the revised IPSS at transplant in patients with myelodysplastic syndrome/transformed acute myelogenous leukemia receiving allogeneic stem cell transplantation: a retrospective analysis of the EBMT chronic malignancies working party. Bone Marrow Transplant 52:1519-1525

43. Della Porta MG, Alessandrino EP, Bacigalupo A, van Lint MT, Malcovati M, Pascutto C et al (2014) Predictive factors for the outcome of allogeneic transplantation in patients with MDS stratified according to the revised IPSS-R. Blood 123:2333-2342

Publisher's Note Springer Nature remains neutral with regard to jurisdictional claims in published maps and institutional affiliations. 